\title{
Cancer Stem Cell
}

National Cancer Institute

\section{Source}

National Cancer Institute. Cancer Stem Cell. NCI Thesaurus. Code C68706.

A malignant cell which may derive from mutations in normal stem cells. Cancer stem cells proliferate and give rise to other malignant cells. They may be present in very small numbers in the tumor and may not be present in all tumors. Many investigators believe that cancer stem cells cause relapse of the tumor and that novel cancer therapies should specifically target those cells. 